\title{
Clindamycin resistant emm33 Streptococcus pyogenes emerged among invasive infections in Helsinki metropolitan area, Finland, 2012 to 2013
}

A K Pesolaํㅜ, R Sihvonen¹, L Lindholm², A Pätäri-Sampo (anu.patari-sampo@hus.fi)

1. Division of Clinical Microbiology, HUSLAB, Helsinki University Hospital, Helsinki, Finland

2. National Institute for Health and Welfare, Department of Infectious Disease Surveillance and Control, Turku, Finland

Citation style for this article:

Pesola AK, Sihvonen R, Lindholm L, Pätäri-Sampo A. Clindamycin resistant emm33 Streptococcus pyogenes emerged among invasive infections in Helsinki

metropolitan area, Finland, 2012 to 2013 . Euro Surveill. 2015;20(18):pii=21117. Available online: http://www.eurosurveillance.org/ViewArticle.aspx?Articleld=21117

Article submitted on 26 April 2014 / published on 07 May 2015

In 2012, blood, skin and soft tissue infections caused by clindamycin resistant Streptococcus pyogenes (group A streptococcus; GAS) appeared to be increasing in the Helsinki metropolitan area. We compared monthly percentages of clindamycin resistant isolates in the area between 2012 and 2013, with those in 2010 and 2011. Resistance frequency in terms of patient age was also studied. We reviewed the medical records of bacteraemic cases in 2012 and 2013 and linked the data to emm types. To inform on the emm distribution among GAS isolated from skin and soft tissue infections during the epidemic, GAS isolates of one month (March 2013) were emm typed. For GAS blood, skin, and soft tissue isolates taken together, the proportions of clindamycin resistant isolates were significantly higher in 2012 and 2013 (23\% and 17\%, respectively) compared with the two previous years ( $3 \%$, p<0,001). The erythromycin resistance percentages were almost equal to clindamycin ( $22 \%$ and $17 \%$ ) in 2012 and 2013, respectively. Clindamycin resistance was most frequent in GAS isolates of 40 to 60 year-old patients (148/417; 36\%). Among clindamycin resistant isolates, 12 of 14 blood isolates from 2012 to 2013, and 11 of 13 skin and soft tissue isolates from March 2013, were emm33. Emm33 GAS bacteraemia was associated with clindamycin and erythromycin resistance (odds ratio (OR): 7.0; 95\% confidence interval (CI): 1.9-25.3). Infection focus was mainly the skin; either cellulitis (7/12) or necrotising fasciitis (3/12). All emm33 GAS isolates harboured the ermTR resistance gene with constitutive macrolides, lincosamides and streptogramines B $\left(\mathrm{MLS}_{\mathrm{B}}\right)$ phenotype. Emm33 GAS was responsible for the higher proportion of clindamycin resistance in skin, soft tissue, and blood isolates locally in 2012 and 2013.

\section{Introduction}

Streptococcus pyogenes (group A streptococcus; GAS) causes pharyngitis, skin and soft tissue infections, and invasive septic diseases [1]. Certain GAS emm types have been associated with tissue-specific infections [2], antibiotic resistance [3], and local epidemics [3]. Erythromycin resistance has been linked to various emm types, such as 4, 6, 12, 75, and 77 [4-7]. Most of these emm types have been identified in throat isolates.

Depending on the erythromycin resistance mechanism, isolates may also be resistant to clindamycin, although relatively rarely [8].

There is limited information concerning clindamycin resistance in GAS isolates causing skin and soft tissue infections. In Finland, the annual percentages of erythromycin and clindamycin resistance was only 2 to $3 \%$ in 2012 when all GAS isolates (including throat isolates) were analysed together [9]. The figures for all GAS isolates have been the same also in Helsinki metropolitan area [10]. In February 2013, while making the annual local antibiotic resistance statistics of 2012, a high proportion of clindamycin resistance was noticed among blood, skin and soft tissue GAS isolates.

In this study, we investigated whether a specific emm type was behind this phenomenon, by examining the laboratory data of GAS isolates in 2012 and 2013 in the Helsinki metropolitan area. We used baseline data of years 2010 and 2011 for comparison. The invasive GAS cases of 2012 and 2013 were analysed in detail and linked to emm types (blood isolates) to characterise common denominators behind the increase in clindamycin resistance. To obtain more information on the emm distribution in GAS isolates from skin and soft tissue infections, emm typing was performed on a set of such GAS isolates obtained during March 2013 in the Helsinki metropolitan area. 


\section{Methods}

\section{Setting}

In Finland, the Division of Clinical Microbiology at HUSLAB is a clinical diagnostic laboratory that serves the Helsinki metropolitan area of ca 1.5 million population. It receives from the local laboratories all blood cultures flagged positive for bacteria by the BacT/ ALERT3D system (bioMerieux, Marcy l'Etoile, France) for bacterial identification and resistance analyses. The GAS blood isolates are routinely stored and sent to the national reference laboratory at the National Institute for Health and Welfare for emm typing. HUSLAB does the final identification and resistance analyses also for all other GAS isolates e.g. throat, skin, and soft tissue isolates of the Helsinki metropolitan area and keeps records of the resistance data for statistical analyses, however the bacterial isolates are not routinely stored. For this study, GAS isolates of skin and soft tissue infections of March 2013 were collected specifically, and stored at $-70^{\circ} \mathrm{C}$. This was done to characterise the emm type distribution of both clindamycin susceptible and resistant GAS isolates from skin and soft tissue infections (while the epidemic was still going on), and to verify if the distribution was the same in these isolates compared with the routinely stored blood isolates. We were able to gather $78 \%(45 / 58)$ of the total skin and soft tissue GAS isolates of the month.

\section{Microbiological methods}

At HUSLAB GAS isolates are routinely identified by colony morphology with betahaemolysis on sheep blood agar and Lancefield grouping with latex agglutination (Latex Reagent A, Oxoid Ltd, Basingstoke, Hants, England). The resistance for erythromycin and clindamycin is routinely determined using the doubledisc diffusion method on Mueller-Hinton agar with $5 \%$ defibrinated horse blood with $20 \mathrm{mg} / \mathrm{L}$ beta-NAD (MH-F broth). In this study, additional minimum inhibitory concentrations (MICs) were determined for the clindamycin resistant skin and soft tissue GAS isolates of March 2013 and blood isolates of 2012 to 2013 after twice sub-culturing on horse blood agar. MICs were determined by Etests (bioMerieux SA, Marcy l'Etoile, France) for azithromycin, clindamycin, doxycycline, erythromycin, levofloxacin, moxifloxacin, tetracycline, and vancomycin, on Mueller-Hinton ( $\mathrm{MH}$ )-F broth using 0.5 McFarland inoculum and incubated for $18 \pm 2 \mathrm{~h}$ with $5 \% \mathrm{CO}_{2}$ at $35 \pm 1{ }^{\circ} \mathrm{C}$. Telithromycin susceptibility was tested by disc-diffusion method in similar conditions as in MIC determinations. European Committee on Antimicrobial Susceptibility Testing (EUCAST) 2013 breakpoints were used to determine whether the zone inhibitions or MICs were considered susceptible (S), intermediate (I) or resistant (R).

$\mathrm{Emm}$ typing and resistance gene analysis of the collected group A streptococcus isolates

At the National Institute for Health and Welfare, the 45 GAS isolates of March 2013 and 109 blood GAS isolates

\section{FIGURE 1}

Percentage of skin, soft tissue, and blood group A streptococcus isolates showing reduced susceptibility to clindamycin and erythromycin in Helsinki metropolitan area, Finland, 2012-2013 $(\mathrm{n}=1,765)$

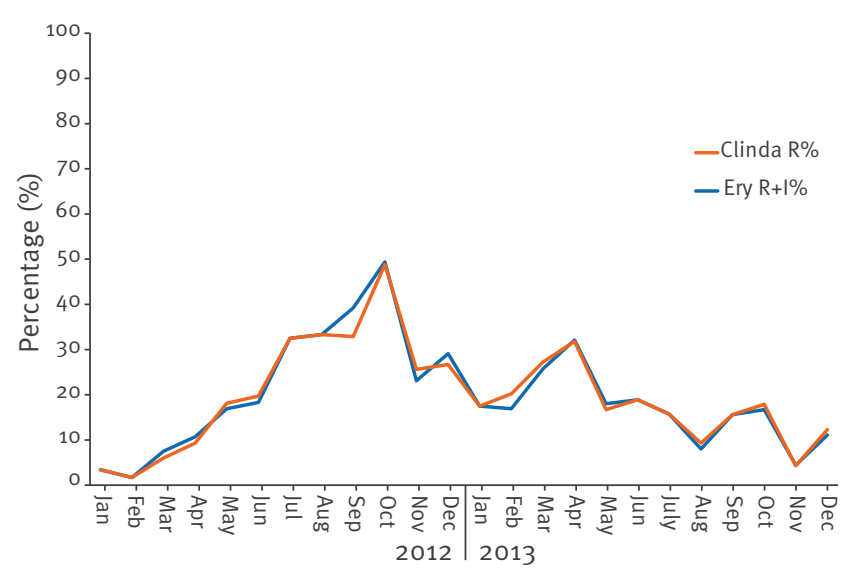

Clinda R\%: percentage of isolates considered resistant to clindamycin according to European Committee on Antimicrobial Susceptibility Testing (EUCAST) 2013 breakpoints; Ery R+1\%: percentage of isolates considered intermediate-resistant and resistant to erythromycin, according to EUCAST 2013 breakpoints.

from 2012 to 2013 were emm typed according to the guidelines provided by Centres for Disease Control and Prevention (http://www2a.cdc.gov/ncidod/biotech/ strepblast.asp) as previously described [11].

DNA of the erythromycin and clindamycin resistant GAS isolates (blood isolates of 2012-2013; $n=14$ and isolates of March 2013; $n=13$ ) was extracted by suspending the colonies in $100 \mu \mathrm{l}$ of TE buffer and boiling for $15 \mathrm{~min}$, followed by centrifugation at $13,000 \mathrm{rpm}$ for $2 \mathrm{~min}$. The presence of erm, including ermB and ermTR, and mefA genes was detected by multiplex-polymerase chain reaction ( $P C R$ ) including primers for amplification of mefA, ermB and ermTR genes, as described previously [12]. Positive controls were $S$. pyogenes A569 for mefA, Escherichia coli with plasmid pJIR229 for ermB, and S. pyogenes A200 for ermTR [13].

\section{Susceptibility data analysis}

The susceptibility analyses of clinical isolates were made using WHONET 5.6 software. We analysed the resistance figures of GAS isolates of the Helsinki metropolitan area between January 2012 and December 2013, and compared the data to the baseline years, namely 2010 and 2011. Blood, skin, and soft tissue isolates were analysed separately from throat isolates. One isolate per patient, the most resistant one, was included in the analysis (WHONET definition). Data were expressed as percentage of isolates resistant or intermediate for erythromycin together and as percentage of isolates resistant for clindamycin, according to the EUCAST 2013 standard (http://www.eucast. org). The reason for this was that the standard did not include a zone diameter breakpoint for intermediate 


\section{FIGURE 2}

Clindamycin susceptibility of skin, soft tissue, and blood group A streptococcus isolates by age group, Helsinki metropolitan area, Finland, 2012-2013 $(n=1,765)$

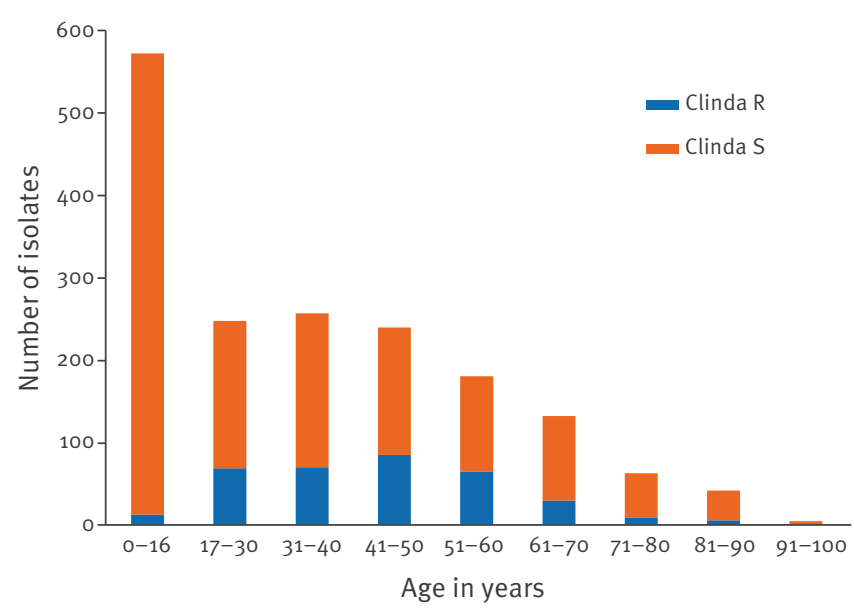

Clinda R: resistant to clindamycin; Clinda S: susceptible to clindamycin.

for clindamycin, but for erythromycin it did. Inducible clindamycin resistance was detected by antagonism of clindamycin activity by erythromycin (the D phenomenon) and if not present the isolate was reported susceptible. In HUSLAB the detected antagonism was reported resistant for clindamycin.

\section{Analysis of clinical data and statistics}

Electronic medical records of patients with a GAS positive blood culture between January 2012 and December 2013 in Helsinki metropolitan area were reviewed to identify underlying conditions and any common exposure between the patients. Age, sex, C-reactive protein (CRP) value, and leucocyte count at the time of diagnosis were registered. Diagnosed diabetes was recorded. Alcohol abuse was defined as a known social or medical problem caused by alcohol noted in the medical records. Intravenous drug abuse was registered similarly when mentioned in the records. Suspected focus of infection was registered. Presence of a cutaneous infection was described as either cellulitis (infections of the skin and underlying tissues such as erysipelas and deeper non-necrotising soft-tissue infection) or necrotising fasciitis (progressive, destructive, subcutaneous streptococcal infection with necrosis observed either directly or under surgery). Need for surgical procedures, complications, and stay at an intensive care unit due to GAS bacteraemia was recorded. Mortality within seven days after GAS positive blood culture was recorded. Data were analysed and compared using Fisher's exact or Pearson chi-squared tests, or t-test, Mann-Whitney U-test or analysis of variance (ANOVA), when appropriate, using SPSS for Windows statistical package (SPSS Inc., Chicago, IL). Logistic regression analysis was used to identify the risk factors. A p-value $<0.05$ was considered statistically significant.

\section{Results}

Resistance data of clinical group A streptococcus isolates

When the resistance data were analysed without throat isolates, the proportions of skin, soft tissue, and blood GAS isolates obtained from Helsinki metropolitan area that were clindamycin resistant in 2012 and 2013 were respectively $23 \%(199 / 866)$ and $17 \%(153 / 899)$. The baseline figures were $3 \%(22 / 745)$ in 2010 and $3 \%(24 / 734)$ in 2011 ( $p<0,001 ; 2012$ and 2013 figures compared with 2010 and 2011 figures). The proportions of erythromycin intermediate-resistant and resistant isolates were almost equal to those for clindamycin, namely $22 \%(191 / 866)$ and $17 \%(152 / 899)$ in 2012 and 2013 , respectively. Baseline proportions of erythromycin intermediate-resistant and resistant isolates were $4 \%(26 / 745)$ and $5 \%(33 / 734)$ in 2010 and 2011 ( $p<0,001 ; 2012$ and 2013 figures compared with 2010 and 2011 figures), respectively.

The increase in proportion of isolates with clindamycin resistance began in the spring 2012 and was the highest at 49\% (40/82) in October 2012 (Figure 1).

At the end of the study period, in December 2013, still $12 \%(10 / 81)$ of skin, soft tissue, and blood GAS isolates were clindamycin resistant. The proportion of clindamycin resistant isolates varied between age groups, and was highest in the 41 to $50(35 \% ; 84 / 238)$ and 51 to 60 year-olds $(36 \% ; 64 / 179)$, and lowest among those < 16 years of age $(2 \% ; n=12 / 569$; Figure 2$)$.

The proportion of clindamycin resistant throat isolates remained at the baseline level being $3 \%(233 / 8,953)$, and $4 \%(354 / 9,083)$ in 2012 and 2013 , respectively. The proportion of throat isolates which were intermediate-resistant or resistant to erythromycin were also

\section{FIGURE 3}

Emm type distribution of invasive group A streptococcus isolates, Helsinki metropolitan area, Finland, 2012-2013 $(\mathrm{n}=109)$

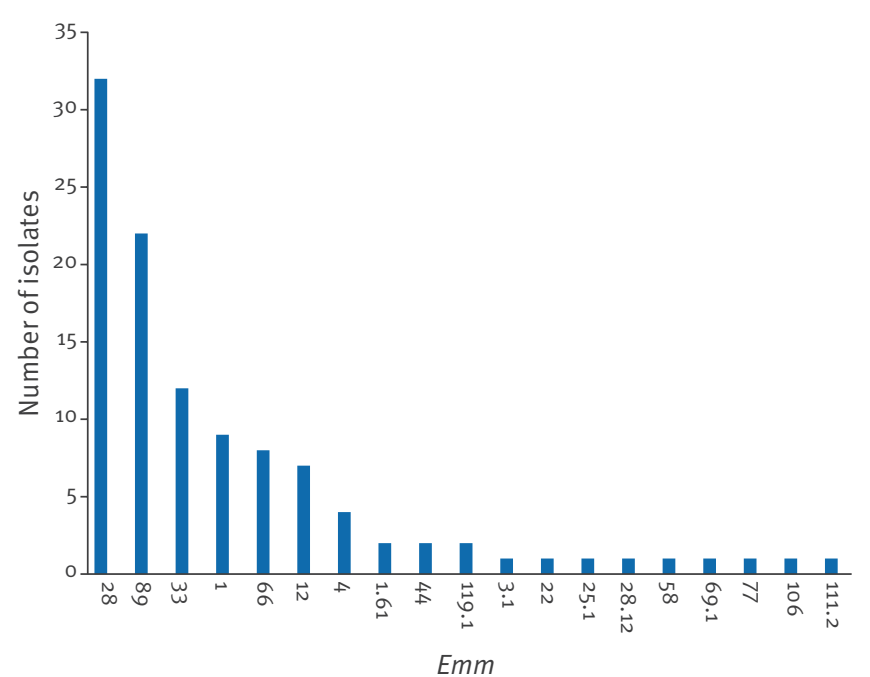


$3 \%(278 / 8,953)$ and $4 \%(391 / 9,083)$ in 2012 and 2013 , respectively.

Emm types, clindamycin resistance, and clinical data of invasive group A streptococcus cases in 2012 and 2013

A total of 109 GAS positive blood isolates were identified in the Helsinki metropolitan area between January 2012 and December 2013. Figure 3 shows the emm type distribution of these invasive isolates.

Of the 109 GAS positive blood isolates, 14 were clindamycin resistant and these included $12 \mathrm{emm} 33$, one emm28, and one emm89. Figure 4 shows the time distribution of the invasive GAS isolates resistant or sensitive for clindamycin with respective resistance genes. None of the emm33 isolates were susceptible for clindamycin. During the baseline years 2010 and 2011, when clindamycin resistance among isolates was at a low level, no invasive emm33 GAS were isolated in the Helsinki metropolitan area.

Table 1 compares the clinical data of emm33 cases to the cases with another emm type. In logistic regression analysis clindamycin and erythromycin resistance, alcoholism, and intravenous drug abuse (Table 1) associated with emm33 GAS bacteraemia. Of the 12 emm 33 cases, 10 had infection focus on the skin or soft tissue. Three emm33 cases underwent a surgical procedure due to complications of GAS infection. There were no re-infections or need for intensive care in emm33 cases.

Emm types and laboratory referral data of skin and soft tissue group A streptococcus isolates of March 2013

A total of 45 GAS isolates from skin and soft tissue infections were gathered in March 2013 and emm typed. Emm typing revealed two isolates being

S. dysgalactiae subsp. equisimilis and these were discarded from the analysis. The remaining 43 isolates represented emm types shown in Figure 5. Of these, 13 showed clindamycin resistance and these included 11 , which were emm33. None of the emm33 were susceptible for clindamycin. Ten emm33 isolates were from a skin lesion or abscess as shown by the laboratory referral data in Table 2.

\section{FIGURE 4}

Time distribution of invasive group A streptococcus isolates, Helsinki metropolitan area, 2012-2013 (n = 109)

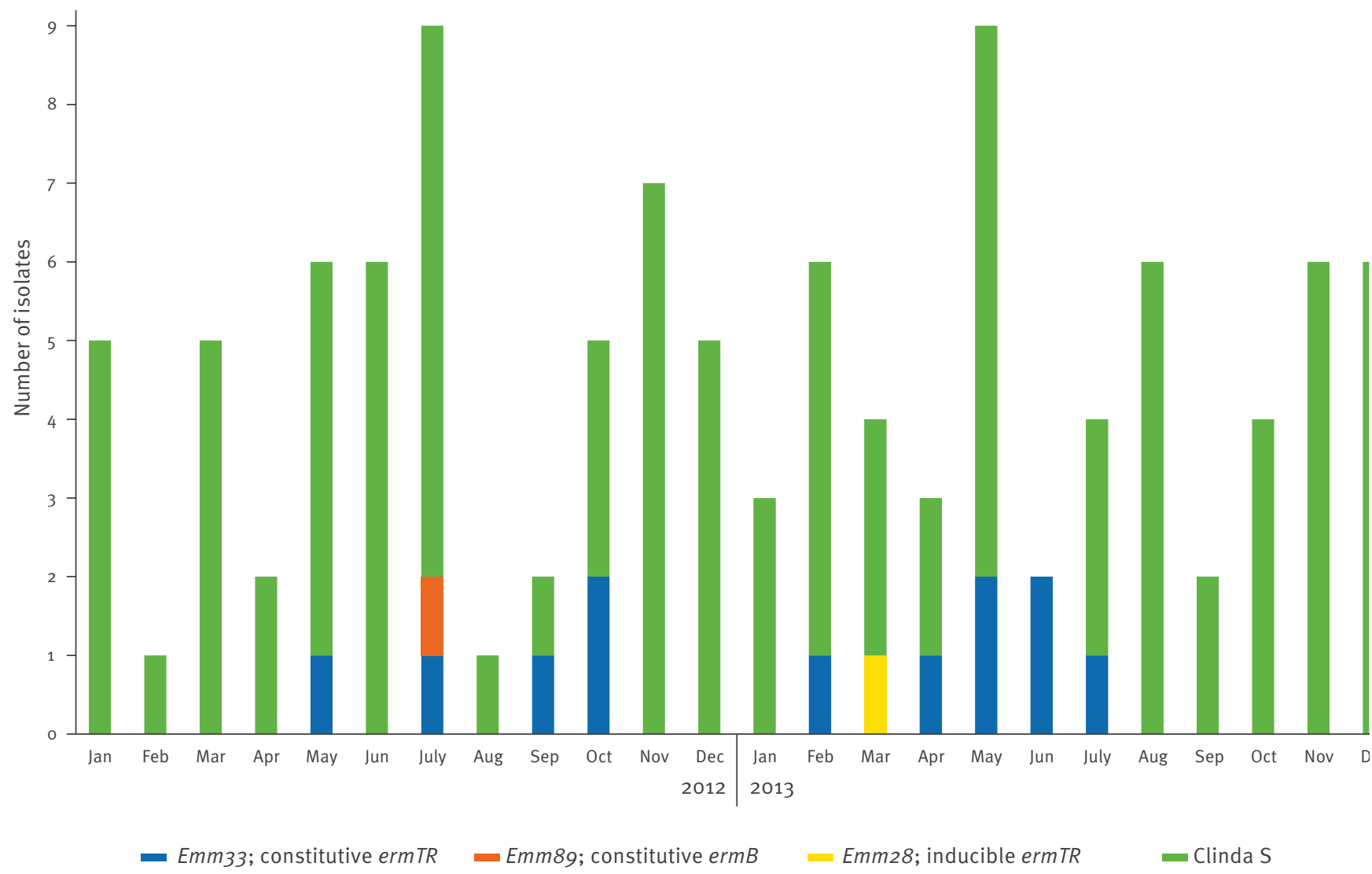


Invasive emm33 cases compared with invasive non-emm33 cases, Helsinki metropolitan area, Finland, 2012-2013 (n = 109)

\begin{tabular}{|c|c|c|c|c|}
\hline & Emm33 & Non-emm33 & $\mathrm{P}$ & OR $(95 \% \mathrm{Cl})$ \\
\hline Number of cases (male/female) & $12(7 / 5)$ & $97(47 / 50)$ & NS & - \\
\hline Age in years: mean (range) & $54(22-80)$ & $51(0-89)$ & NS & - \\
\hline C-reactive protein in $\mathrm{mg} / \mathrm{L}$ : mean (range) & $164(4-393)$ & $189(4-573)$ & NS & - \\
\hline Leucocyte count: mean (range) & $13(4-26)$ & $14(1-39)$ & NS & - \\
\hline Cases with alcohol abuse: $\mathrm{n} / \mathrm{N}$ & $8 / 12$ & $17 / 97$ & $<0.001$ & $11.9(2.9-49.7)$ \\
\hline Cases with intravenous drug abuse: $\mathrm{n} / \mathrm{N}$ & $4 / 12$ & $5 / 97$ & $<0.01$ & $9.1(2.0-40.8)$ \\
\hline Cases with erythromycin resistant isolates $\mathrm{s}^{\mathrm{a}} \mathrm{n} / \mathrm{N}$ & $12 / 12$ & $2 / 97$ & $<0.001$ & $7.0(1.9-25.3)$ \\
\hline Cases with clindamycin resistance: $\mathrm{n} / \mathrm{N}$ & $12 / 12$ & $2 / 97$ & $<0.001$ & $7.0(1.9-25.3)$ \\
\hline Cases with cellulitis: $\mathrm{n} / \mathrm{N}$ & $7 / 12$ & $41 / 97$ & NS & - \\
\hline Cases with necrotising fasciitis: $\mathrm{n} / \mathrm{N}$ & $3 / 12$ & 4/97 & NS & - \\
\hline Cases with diabetes: $\mathrm{n} / \mathrm{N}$ & $3 / 12$ & $18 / 97$ & NS & - \\
\hline 7-day mortality: $\mathrm{n} / \mathrm{N}$ & $0 / 12$ & $4 / 97$ & NS & - \\
\hline
\end{tabular}

$\mathrm{Cl}$ : confidence interval; OR: odds ratio; NS: not significant, $\mathrm{p}>0.05$.

a Including intermediate-resistant and resistant isolates, according to EUCAST 2013 breakpoints.

Susceptibility and resistance genes of the collected emm33 group A streptococcus isolates All studied emm33 GAS (skin and soft tissue isolates of March 2013 and blood isolates of 2012-2013, totally $n=23$ ) showed the constitutive macrolides, lincosamides and streptogramines $B\left(M L S_{B}\right)$ phenotype with similar antibiotic resistance profiles and harboured the ermTR resistance gene. The isolates were non-susceptible for azithromycin (MIC range: $12->256 \mathrm{mg} / \mathrm{L}$ ), clindamycin (all MICs>256 mg/L), and erythromycin (MIC range: $2-8 \mathrm{mg} / \mathrm{L}$ ). They showed susceptibility for doxycycline (MIC range: $0.125-0.38 \mathrm{mg} / \mathrm{L}$ ), levofloxacin (MIC range: $0.25-0.75 \mathrm{mg} / \mathrm{L}$ ), moxifloxacin (MIC range: $0.064-0.19 \mathrm{mg} / \mathrm{L}$ ), tetracycline (MIC range: $0.25-1.0$ $\mathrm{mg} / \mathrm{L}$ ), and vancomycin (MIC range: $0.38-0.75 \mathrm{mg} / \mathrm{L}$ ). All isolates were susceptible for telithromycin (discdiameter range: $27-38 \mathrm{~mm}$ ), which was tested by discdiffusion method.

\section{Discussion}

During 2012 and 2013 emm33 GAS caused a local epidemic of skin and soft tissue infections in the adult population in Helsinki metropolitan area, Finland. The outbreak was detected as a marked increase in the proportion of isolates resistant to erythromycin and clindamycin. In most cases the primary infection focus was the skin, but a few GAS emm33 infections were invasive and caused necrotising fasciitis. All emm33 isolates were resistant to both erythromycin and clindamycin.

There was an association of emm33 with alcohol and intravenous drug abuse, however the number of patients was very low so these results have to be interpreted with caution. Alcohol abuse was marked positive if mentioned in the patient records. Since alcoholism is not always evident and not even always actively asked about by the doctor in the hospital, this information is most probably partly lacking from our data. The same counts for intravenous drug abuse. An association with alcohol abuse has nevertheless been reported for certain other emm types, such as emm59 and $e m m 1[14,15]$.

Emm33 belongs to the emm superfamily group D, which includes emm types causing skin infections, such as impetigo $[2,16]$. Emm33 has further been characterised as a member of the $\mathrm{D}_{4} \mathrm{emm}$-cluster, which is able to bind plasminogen [17]. Plasminogen binding may contribute to the skin tissue tropism by possible break down of tissue barriers facilitating dissemination and prolonged bacterial persistence in the skin [18]. There is limited data concerning infections caused by this emm type. It caused some of the severe GAS infections of intravenous drug users reported in a study in the United Kingdom (UK) in 2003 and 2004, but was

\section{FIGURE 5}

Emm type distribution of skin and soft tissue group A streptococcus isolates, Helsinki metropolitan area, Finland, March $2013(\mathrm{n}=43)$

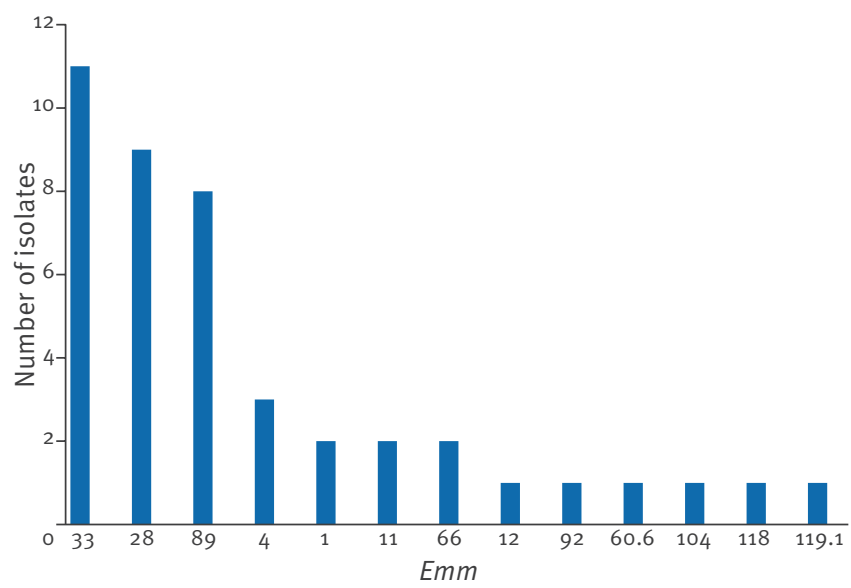




\section{TABLE 2}

Laboratory referral data of the group A streptococcus isolates from skin and soft tissue that were clindamycin resistant, Helsinki metropolitan area, Finland, March 2013 $(\mathrm{n}=13)$

\begin{tabular}{|c|c|c|c|c|}
\hline Sex & $\begin{array}{l}\text { Age groups } \\
\text { in years }\end{array}$ & $\begin{array}{l}\text { Emm } \\
\text { type }\end{array}$ & $\begin{array}{l}\text { Resistance } \\
\text { gene }\end{array}$ & Infection focus \\
\hline Female & $81-90$ & 33 & ermTR ${ }^{a}$ & $\begin{array}{l}\text { Decubital wound, } \\
\text { sacrum }\end{array}$ \\
\hline Male & $31-40$ & 33 & ermTR ${ }^{a}$ & Auricular canal \\
\hline Male & $41-50$ & 33 & ermTR ${ }^{a}$ & $\begin{array}{l}\text { Suppurative wounds, } \\
\text { foot and elbow }\end{array}$ \\
\hline Female & $31-40$ & 33 & ermTR ${ }^{a}$ & $\begin{array}{c}\text { Postoperative } \\
\text { wound infection, } \\
\text { gynaecological }\end{array}$ \\
\hline Female & $51-60$ & 33 & ermTR ${ }^{a}$ & $\begin{array}{l}\text { Postoperative wound } \\
\text { infection, ankle }\end{array}$ \\
\hline Male & $41-50$ & 33 & $\operatorname{ermTR}^{a}$ & Abscess, finger \\
\hline Male & $17-30$ & 33 & $\operatorname{ermTR}^{a}$ & Impetigo, perioral \\
\hline Male & $41-50$ & 33 & ermTR ${ }^{a}$ & $\begin{array}{l}\text { Postoperative wound } \\
\text { infection, finger }\end{array}$ \\
\hline Female & $17-30$ & 33 & ermTR ${ }^{a}$ & Abscess, leg \\
\hline Female & $31-40$ & 33 & ermTR ${ }^{a}$ & Nasal discharge \\
\hline Male & $17-30$ & 33 & ermTR ${ }^{a}$ & Impetigo, foot \\
\hline Male & $17-30$ & 92 & $e r m B^{b}$ & $\begin{array}{c}\text { Suppurative wound, } \\
\text { heel }\end{array}$ \\
\hline Male & $61-70$ & 11 & $e r m B^{c}$ & Penile sores \\
\hline
\end{tabular}

a Constitutive ermTR.

Inducible ermB.

Constitutive erm $B$.

not the most common emm type in that study [19]. Intravenous drug abuse has been shown to be a risk factor for severe disease caused by GAS [20].

GAS is able to cause very local and timely limited epidemics, as shown in intravenous drug users in the UK [19]. Interestingly, in 2012 in our neighbouring country, Sweden, there was an increase of invasive emm1 GAS diseases occurring mostly in patients over 80 years of age [21]. The invasive emm1 numbers have remained stable in Helsinki metropolitan area between 2010 and 2013 indicating that the Swedish epidemic is local or has not reached Finland yet.

The Finnish National Institute for Health and Welfare receives all invasive GAS isolates from Finland for genotyping and strain collection. Since 2007 , the main genotyping method has been emm typing. In Finland, the first emm3z invasive GAS isolates were found only in 2012 and they all originated from the Helsinki metropolitan area. From June 2013 onwards sporadic emm33 cases have been found also in other hospital districts, however emm33 still remains an uncommon genotype in Finland (Pieter Smit, personal communication, April 2014).

Several mechanisms underlie the macrolide and lincosamide resistance. $M$ phenotype isolates carry the mefA gene, which causes efflux of the antibiotic and confers resistance to many macrolides with preserved susceptibility to clindamycin and streptogramin B [22]. Emm 4 GAS with mefA has previously caused high erythromycin resistance locally in Finland [23]. Interestingly, in our study none of the tested isolates carried the mefA resistance gene. The resistance data of the Helsinki metropolitan area showed also that most of the isolates with decreased susceptibility to erythromycin were also clindamycin resistant (either with inducible or constitutive phenotype) suggesting that the $M$ phenotype was not generally present in the GAS isolates during the years 2012 to 2013.

Ribosomal methylation of the target of the antibiotics (ermA, ermB or ermTR) prevents binding of the antibiotics by causing a conformational change in the $23 \mathrm{~S}$ ribosome [24]. The ermB isolates usually show constitutive $M L S_{B}\left(C_{M L S}\right)$ resistance to macrolides, clindamycin, and streptogramin B, while the ermA and ermTR isolates may show macrolide-induced resistance to clindamycin [13]. In our study all emm33 isolates shared the ermTR macrolide resistance gene with a $\mathrm{CMLS}_{\mathrm{B}}$ resistance phenotype. This resistance phenotype is more common among erm $B$ but has in rare occasions also been shown by isolates carrying the ermTR gene [25].

All the emm33 isolates were also susceptible to telithromycin. Usually isolates with the $\mathrm{CMLS}_{B}$ phenotype are resistant or intermediate to telithromycin, however, such phenotypes harbour typically the ermB gene [26]. Accordingly, two isolates in our study (a blood emm89 and a skin isolate of March 2013 emm11) with $\mathrm{CMLS}_{B}$ phenotype with ermB gene showed intermediate susceptibility to telithromycin (data not shown). In contrast, an isolate with inducible $\mathrm{MLS}_{\mathrm{B}}$ phenotype with ermB (skin isolate of March 2013 emm92) was susceptible for telithromycin. The only isolate with inducible $M S_{B}$ phenotype with ermTR gene (a blood isolate emm28) was susceptible for telithromycin, as were all the emm33 isolates. Similar results have shown Giovanetti et al. regarding inducible ermTR GAS isolates [27]. All the emm33 isolates in our study showed large disc-diameters growth suppression by telithromycin. Unfortunately at the time of investigation, telithromycin Etests were not available in our laboratory, so we were not able to determine MICs, which would have represented more precise data.

The emm33 isolates in our study were also tetracycline susceptible, while Kataja et al. showed that inducible ermTR GAS isolates in Finland in 1994 and 1995 were mostly tetracycline resistant [25]. To fully understand the resistance mechanism underlying emm33, the isolates should be examined in more detail. The fact that 
emm33 isolates had the same resistance gene and similar antibiotic resistance patterns supports the idea that they belong to the same clone (Pieter Smit, personal communication, April 2014).

Clindamycin is an important drug in the primary healthcare, especially, as it is used for treating GAS infections in penicillin allergic patients. The skin and soft tissue infections of intravenous drug abusers and of diabetic patients are often polymicrobial with anaerobic bacteria and staphylococci present making clindamycin the drug of choice for empirical treatment. In invasive, septic GAS infections clindamycin is used in combination with penicillin for better outcome possibly diminishing the bacterial toxin production [28]. Spreading of a skin-tropic emm type with clindamycin resistance is of concern considering the empirical antibiotic treatment of the abovementioned patient groups. An announcement, aimed at the primary care and hospital doctors of the city of Helsinki, was released in spring 2013 by HUSLAB together with the infectious disease specialists of the Helsinki city hospitals concerning the proportion of clindamycin resistant GAS figures. It guided the empirical therapy of adult skin infections recommending that clindamycin should not have been used as monotherapy. The infectious disease specialists of the whole Helsinki metropolitan area were also informed, and additional antimicrobial susceptibility testing was conducted for the clindamycin resistant GAS isolates to find alternative drugs for penicillinallergic patients. Surveillance of the situation is important because emm33 GAS may spread to children since it is a potential impetigo-causing emm type [2].

The study shows that for resistance statistics it is important to analyse skin and soft tissue GAS separately from the numerous throat GAS. Different emm types are typical for distinct anatomical locations and important resistance phenomena may be masked if isolates are analysed only together. Here we documented a single, local, epidemic of a previously rare emm33 GAS causing skin and soft tissue infections with also invasive cases. This emm type caused rapid changes in macrolide and clindamycin resistance locally in the adult population. These findings had an impact on the empirical treatment of skin and soft tissue infections of the area.

\section{Acknowledgments}

We thank the personnel of the Department of Bacteriology for gathering and analysing the GAS isolates. Tuula Randell is thanked for technical assistance with the erm PCR. Pieter Smit is thanked for his comments and revision of the article.

\section{Conflict of interest}

None declared.
Authors' contributions

Anne-Katrine Pesola investigated the medical records of the bacteraemic patients of years 2012-2013 and was mainly responsible for the statistical analyses. Reetta Sihvonen made the antimicrobial susceptibility testing (MIC determinations) for the resistant skin, soft tissue, and blood GAS isolates and determined the erm genes of the resistant isolates. Laura Lindholm was responsible for the emm typing of the GAS isolates. Anu Pätäri-Sampo made the original finding of the high resistance figures of GAS isolates in the Helsinki metropolitan area. Pätäri-Sampo designed the study, applied for the permission to run the study in HUSLAB, and was primarily responsible for the writing of the manuscript. All authors contributed substantially to the manuscript, and have seen and approved the final version.

\section{References}

1. Cunningham MW. Pathogenesis of group A streptococca infections. Clin Microbiol Rev. 2000;13(3):470-511. http:// dx.doi.org/10.1128/CMR.13.3.470-511.2000 PMID:10885988

2. McMillan DJ, Drèze PA, Vu T, Bessen DE, Guglielmini J, Steer AC, et al. Updated model of group A Streptococcus M proteins based on a comprehensive worldwide study. Clin Microbiol Infect. 2013;19(5):E222-9. http://dx.doi.org/10.1111/14690691.12134 PMID:23464795

3. Metzgar D, McDonough EA, Hansen Cl, Blaesing CR, Baynes $D$, Hawksworth AW, et al. Local changes in rates of group $A$ Streptococcus disease and antibiotic resistance are associated with geographically widespread strain turnover events. Virulence. 2010;1(4):247-53. http://dx.doi.org/10.4161/ viru.1.4.11979 PMID:21178449

4. Perez-Trallero E, Marimón JM, Montes M, Orden B, de Pablos M. Clonal differences among erythromycin-resistant Streptococcus pyogenes in Spain. Emerg Infect Dis. 1999;5(2):235-40. http://dx.doi.org/10.3201/eido502.990207 PMID:10221875

5. Martin JM, Green M, Barbadora KA, Wald ER. Erythromycinresistant group A streptococci in schoolchildren in Pittsburgh. N Engl J Med. 2002;346(16):1200-6. http://dx.doi.org/10.1056/ NEJMoa013169 PMID:11961148

6. Green M, Martin JM, Barbadora KA, Beall B, Wald ER. Reemergence of macrolide resistance in pharyngeal isolates of group a streptococci in southwestern Pennsylvania. Antimicrob Agents Chemother. 2004;48(2):473-6. http://dx.doi. org/10.1128/AAC.48.2.473-476.2004 PMID:14742197

7. Reinert RR, Lütticken R, Sutcliffe JA, Tait-Kamradt A, Cil MY, Schorn HM, et al. Clonal relatedness of erythromycin-resistant Streptococcus pyogenes isolates in Germany. Antimicrob Agents Chemother. 2004;48(4):1369-73. http://dx.doi. org/10.1128/AAC.48.4.1369-1373.2004 PMID:15047546

8. Richter SS, Heilmann KP, Beekmann SE, Miller NJ, Miller AL, Rice CL, et al. Macrolide-resistant Streptococcus pyogenes in the United States, 2002-2003. Clin Infect Dis. 2005;41(5):599608. http://dx.doi.org/10.1086/432473 PMID:16080080

9. Gunell M, Hakanen A, Jalava J, Nissinen A, Rantakokko-Jalava $\mathrm{K}$, Saha K, et al. Antimicrobial Resistance in Finland - Finres. 2012. Helsinki: National Institute of Health and Welfare; 2012. Available from: http://urn.fi/URN:ISBN:978-952-302-183-9

10. Vaara M. HUSRES Annual Report 2012. HUS; 2012. Available from: http://www.hus.fi/ammattilaiselle/ huslab-ammattilaisille/tilastot/Bakteerilydsten $\% 20$ mikrobilkeherkkyystilastoja\%2oHelsin/Herkkyystilastot $\% 20$ (Helsinki\%20ja\%20Uusimaa)\%202012.pdf

11. Siljander T, Karppelin M, Vähäkuopus S, Syrjänen J, Toropainen M, Kere J, et al. Acute bacterial, nonnecrotizing cellulitis in Finland: microbiological findings. Clin Infect Dis. 2008;46(6):855-61. http://dx.doi.org/10.1086/527388 PMID:18260753

12. Jalava J, Marttila H. Application of molecular genetic methods in macrolide, lincosamide and streptogramin resistance diagnostics and in detection of drug-resistant Mycobacterium tuberculosis. APMIS. 2004;112(11-12):838-55. http:// dx.doi.org/10.1111/j.1600-0463.2004.apm11211-1209.x PMID:15638840

13. Seppälä H, Skurnik M, Soini H, Roberts MC, Huovinen P. A novel erythromycin resistance methylase gene (ermTR) in Streptococcus pyogenes. Antimicrob Agents Chemother. 1998;42(2):257-62. PMID:9527769

14. Tyrrell GJ, Lovgren M, St Jean T, Hoang L, Patrick DM, Horsman $\mathrm{G}$, et al. Epidemic of group A Streptococcus M/emm59 causing 
invasive disease in Canada. Clin Infect Dis. 2010;51(11):1290-7. http://dx.doi.org/10.1086/657068 PMID:21034198

15. Eriksson BK, Andersson J, Holm SE, Norgren M.

Epidemiological and clinical aspects of invasive group $A$ streptococcal infections and the streptococcal toxic shock syndrome. Clin Infect Dis. 1998;27(6):1428-36. http://dx.doi. org/10.1086/515012 PMID:9868656

16. Bessen DE, Sotir CM, Readdy TL, Hollingshead SK. Genetic correlates of throat and skin isolates of group A streptococci. J Infect Dis. 1996;173(4):896-900. http://dx.doi.org/10.1093/ infdis/173.4.896 PMID:8603968

17. Svensson MD, Sjöbring U, Bessen DE. Selective distribution of a high-affinity plasminogen-binding site among group A streptococci associated with impetigo. Infect Immun. 1999;67(8):3915-20. PMID:10417156

18. Sanderson-Smith M, De Oliveira DMP, Guglielmini J, McMillan DJ, Vu T, Holien JK, et al.; M Protein Study Group. A systematic and functional classification of Streptococcus pyogenes that serves as a new tool for molecular typing and vaccine development. J Infect Dis. 2014;210(8):1325-38. http://dx.doi. org/10.1093/infdis/jiu260 PMID:24799598

19. Lamagni TL, Neal S, Keshishian C, Hope V, George R, Duckworth G, et al. Epidemic of severe Streptococcus pyogenes infections in injecting drug users in the UK, 20032004. Clin Microbiol Infect. 2008;14(11):1002-9. http://dx.doi. org/10.1111/j.1469-0691.2008.02076.x PMID:19040471

20. Lamagni TL, Darenberg J, Luca-Harari B, Siljander T, Efstratiou A, Henriques-Normark B, et al.; Strep-EURO Study Group. Epidemiology of severe Streptococcus pyogenes disease in Europe. J Clin Microbiol. 2008;46(7):2359-67. http://dx.doi. org/10.1128/JCM.00422-08 PMID:18463210

21. Darenberg J, Henriques-Normark B, Lepp T, Tegmark-Wisell K, Tegnell A, Widgren K. Increased incidence of invasive group A streptococcal infections in Sweden, January 2012-February 2013. Euro Surveill. 2013;18(14):20443. http://dx.doi. org/10.2807/1560-7917.ES2013.18.14.20443 PMID:23594518

22. Sutcliffe J, Tait-Kamradt A, Wondrack L. Streptococcus pneumoniae and Streptococcus pyogenes resistant to macrolides but sensitive to clindamycin: a common resistance pattern mediated by an efflux system. Antimicrob Agents Chemother. 1996;40(8):1817-24. PMID:8843287

23. Kataja J, Huovinen P, Muotiala A, Vuopio-Varkila J, Efstratiou A, Hallas G, et al.; Finnish Study Group for Antimicrobial Resistance. Clonal spread of group A streptococcus with the new type of erythromycin resistance. J Infect Dis. 1998;177(3):786-9. http://dx.doi.org/10.1086/517809 PMID:9498465

24. Leclercq R. Mechanisms of resistance to macrolides and lincosamides: nature of the resistance elements and their clinical implications. Clin Infect Dis. 2002;34(4):482-92. http:// dx.doi.org/10.1086/324626 PMID:11797175

25. Kataja J, Huovinen P, Skurnik M, Seppälä H; The Finnish Study Group for Antimicrobial Resistance. Erythromycin resistance genes in group A streptococci in Finland. Antimicrob Agents Chemother. 1999;43(1):48-52. PMID:9869564

26. Bemer-Melchior P, Juvin M-E, Tassin S, Bryskier A, Schito GC, Drugeon H-B. In vitro activity of the new ketolide telithromycin compared with those of macrolides against Streptococcus pyogenes: influences of resistance mechanisms and methodological factors. Antimicrob Agents Chemother. 2000;44(11):2999-3002. http://dx.doi.org/10.1128/ AAC.44.11.2999-3002.2000 PMID:11036012

27. Giovanetti E, Montanari MP, Marchetti F, Varaldo PE. In vitro activity of ketolides telithromycin and HMR 3004 against italian isolates of Streptococcus pyogenes and Streptococcus pneumoniae with different erythromycin susceptibility. J Antimicrob Chemother. 2000;46(6):905-8. http://dx.doi. org/10.1093/jac/46.6.905 PMID:11102408

28. Zimbelman J, Palmer A, Todd J. Improved outcome of clindamycin compared with beta-lactam antibiotic treatment for invasive Streptococcus pyogenes infection. Pediatr Infect Dis J. 1999;18(12):1096-100. http://dx.doi. org/10.1097/00006454-199912000-00014 PMID:10608632 